\title{
MOBILIDADES, COMÉRCIO E CONSUMO DA FEIRA DE LEIRIA: CONFLITOS DE UMA CENTRALIDADE TEMPORÁRIA
}

\author{
Virgílio Manuel Pereira Bernardino ${ }^{1}$ \\ MÁRCIO MENDES ROCHA ${ }^{2}$
}

\begin{abstract}
Resumo - As feiras são manifestações da vida humana sobre os espaços públicos e permitem compreender os deslocamentos dos trabalhadores e dos consumidores do setor. Este artigo debate alguns elementos da centralidade temporária da feira de Leiria e a natureza dialética dos fenômenos sociais subjacentes a estas práticas socioeconômicas e espaciais. A metodologia de pesquisa, adota o critério quantitativo-qualitativo. Amparados em entrevistas a feirantes e consumidores, levantamentos do volume de utentes, fotos e mapas temáticos, desejamos contribuir para o conhecimento do universo da feira de Leiria. Os resultados mostram que as feiras desta cidade são relevantes como centros de abastecimento e consumo para a urbe, haja em vista a grande quantidade de consumidores que as frequentam. Assim, pode-se dizer que a centralidade temporária criada pela feira se constrói em diferentes escalas: a intraurbana e a interurbana.
\end{abstract}

Palavras-chave: Mobilidade, comércio, feira, centralidade temporária, Leiria, Portugal

Abstract - MOBILITIES, TRADE AND CONSUMPTION AT LEIRIA FAIR: CONFLICTS OF A TEMPORARY CENTRALITY. Fairs are manifestations of human life in public spaces, and allow us to understand the movements of workers and consumers in open-air markets. This article discusses certain elements of temporary centrality of the Leiria Fair, as well as the dialectic nature of the social phenomena that underlie these socioeconomic and spatial practices. The research methodology adopts quantitative and qualitative criteria. Based on interviews with vendors and consumers, user volume surveys, photos and thematic maps, we wish to contribute to broaden the knowledge on the Leiria Fair universe. The results show that the fairs that take place in Leiria are relevant as supply and consumption centres for the town, given the large number of consumers who patronise it. Thus, it can be said that the temporary centrality created by the fair is built on different scales: intra-urban and interurban.

Keywords: Mobility, trade, consumption, fair, temporary centrality, Leiria, Portugal

Recebido: Novembro 2013. Aceite: Dezembro 2014.

1 Doutorando em Geografia pela Universidade Estadual de Maringá (UEM) e professor da Universidade Estadual do Paraná (FECILCAM), Brasil. E-mail: virgilio_fecilcam@yahoo.com.br. Bolsista da CAPES-Processo no 8818-11-8.

2 Professor do Programa de Pós-Graduação em Geografia da Universidade Estadual de Maringá (UEM), Brasil, e coordenador do Núcleo de Estudos de Mobilidade e Mobilização. E-mail: mmrocha@uem.br 
Résumé - MOBILITÉ, COMMERCE ET CONSOMMATION À LA FOIRE DE LEIRIA: LES CONTRADICTIONS D'UNE CENTRALITÉ TEMPORAIRE. Les foires sont une manifestation d'activités humaines dans un espace public qui permet de comprendre les déplacements de travailleurs et de clients de la région. On étudie divers aspects de la centralité temporaire due à la foire de Leiria et la nature dialectique des phénomènes sociaux sous-jacents à ces pratiques sociales, économiques et spatiales. La recherche a été menée selon un critère quantitatif et qualitatif. En utilisant des entrevues de marchands et de clients, des relevés volumétriques de participants, des photos et des cartes thématiques, on a cherché à faire connaître l'univers qu'est la foire de Leiria. On voit qu'elle est un très important centre de ravitaillement et de consommation pour la ville, mais que la centralité temporaire crée par cette foire présente deux échelles distinctes : intra-urbaine et interurbaine.

Mots clés: Mobilité, commerce, foire, centralité temporaire, Leiria, Portugal.

摘要一雷利亚市集的流动性、商业活动和消费情况：由一种暂时向心性引起的冲突。市 集是人们投于公共空间上的生活表现, 我们从而明白到该行业的工作者和消费者的动态。本文将 讨论䏌于雷利亚市集的暂时向心性的若干问题, 以及这些社会经济和空间性质行为底下的社会现 象所包含的辩证意义, 采用的方法是数量和质量并重。透过访问市集商贩和消费者、收集访客人 数、有矢照片及地图, 我们希望可以帮助了解雷利亚市集这个小宇宙。所得结果显示市集对该城 市来说是重要的供应和消费枢纽, 这可见于访客的庞大数目, 再由此推断市集构成的暂时向心性 是建立于不同尺度基础之上：市内和市际的。

矣键字: 流动性、商业、消费、市集、暂时向心性、雷利亚、葡萄牙。

\section{INTRODUÇÃO}

As feiras são grandes superfícies de comércio não sedentário (Henriques, 2012) que se apoiam fundamentalmente nas mobilidades de feirantes e consumidores, para que a sua organização comercial e trocas de produtos naturais ou artificiais, circulação e negócio se materializem. Constituem uma das formas de fazer comércio mais antigas da humanidade, que contribuiram significativamente para o surgimento e desenvolvimento do capitalismo. Inicialmente caracterizavam-se pela troca entre produtores que possuíam produtos excedentes em determinadas regiões por outros bens também excedentes em outras regiões, resultantes de uma economia agrícola para o autoconsumo.

De origem pouco conhecida, as feiras constituem um dos aspectos mais importantes da Idade Média (Rau, 1983), e protagonizaram o desenvolvimento das cidades no renascimento comercial observado no século XIII. Segundo Leo Huberman (1976), à medida que a produção agrícola se foi desenvolvendo nos feudos, o excedente passou a ser comercializado nos aglomerados urbanos com as feiras. As trocas comerciais possibilitaram a padronização dos meios de troca e atuaram de maneira decisiva na superação do modelo feudal.

Estabelecidas estrategicamente em lugares onde os fluxos de comerciantes e populares se encontravam, com a consolidação do capitalismo as feiras estimularam, nas cidades, a criação de uma estrutura bancária que permitisse o comércio monetarizado (Huberman, 1976). 
A feira é entendida, neste estudo, como um mercado periódico, de levante. Ou seja, os mercados periódicos configuram-se pela sincronização espacio-temporal da atividade mercantil, em que os dias de funcionamento de cada feira se encontram articulados aos das demais numa relação de tempo e espaço, englobando mobilidade circulatória periódica e sincronizada de feirantes e consumidores de um determinado mercado. Desse modo, feirantes e consumidores se reúnem a cada dia num determinado nó do espaço geográfico, para onde convergem os consumidores, geralmente de áreas próximas (Corrêa, 1994).

Conforme Derruau (1982: 82), "A feira é um mercado periódico que é acompanhado [...] por uma atmosfera de festa". A lei portuguesa considera feira um "evento autorizado pela respectiva autarquia, que congrega periodicamente no mesmo espaço vários agentes de comércio a retalho que exercem a actividade de feirante", e feirante, como "comerciante de retalho que exerce esse comércio de forma não sedentária em mercados e feiras" (Henriques, 2012: 15).

Nesse ínterim, as feiras constituem um dos feitos mais importantes da organização econômica da Idade Média. Surgidas da necessidade de promover a permuta de produtos entre o camponês e o citadino, elas representam o ponto de encontro entre o produtor e o consumidor; o ponto onde se concentrou a vida mercantil de uma época em que a circulação de pessoas e mercadorias era dificultada pela falta de comunicações, pela pouca segurança das jornadas e pela carestia de portagens e peagens (Rau, 1983: 33).

Contemporaneamente, à semelhança do que ocorria séculos atrás, as trocas nas feiras ainda são realizadas por sujeitos de diferentes lugares, com seus diversos produtos. A mobilidade de feirantes, mercadorias e consumidores para a efetivação das trocas é uma das características desses eventos itinerantes. As feiras reciclam os espaços geográficos, lhes dão múltipla funcionalidade, possibilitando a sobrevivência dos pequenos produtores, pequenos comerciantes, ciganos e prestadores de serviços, e oportunizam também a concentração e circulação de clientes no comércio circunvizinho ao locus de trocas.

Com o avanço do capitalismo global, as mobilidades humanas tendem a se mostrar complexas, produzindo novos espaços que procuram absorver as tradicionais estruturas espaciais de comércio, representadas nesta pesquisa pela feira de Leiria.

Quanto à caracterização do problema, sabemos que, atualmente, as feiras estão cercadas de dificuldades, ameaças, conflitos e dúvidas, características da era da globalização, que exigem aptidões dos feirantes para superar as constantes dificuldades. Ressalta-se o papel da feira como dinâmica específica, fruto do acúmulo de processos singulares que se desenvolveram a partir de crises originadas em diferentes tempos (Harvey, 2005). São essas diferenças temporais que caracterizam a produção e reprodução do espaço, já que representam a acumulação desigual de elementos tradicionais e modernos, resultando numa cristalização diferenciada de signos.

Pretendemos, na nossa abordagem, identificar as ideologias e a natureza dialética dos fenômenos sociais subjacentes às práticas espaciais e, desse modo, ressaltar a 
forma como as contradições se verificam no contexto da criação e da reprodução sócio-espacial. Nesse sentido, procuraremos sistematizar aqui a dimensão circulatória dos feirantes e consumidores implícitos nesse processo.

Para alcançar os objetivos, adotamos, quanto à metodologia de pesquisa, o critério quantitativo-qualitativo. Apoiados em leituras, entrevistas a feirantes e consumidores, fotos e mapas temáticos, desejamos contribuir para o conhecimento do universo das feiras e, em particular, da feira de Leiria, na manutenção do tecido social urbano. Assim, apresentamos a mobilidade de feirantes e consumidores como uma das expressões de centralidade exercidas por esta feira, que pode explicar os efeitos do estreitamento da relação local-global na relação cidade-campo.

\section{LEIRIA E SUAS FEIRAS}

O concelho de Leiria localiza-se a norte de Lisboa (Portugal), a uma distância aproximada de $120 \mathrm{~km}$. É, composto por 29 freguesias e conta com 126879 habitantes, segundo os resultados dos Censos 2011 realizados pelo Instituto Nacional de Estatística.

A origem de Leiria perde-se nos tempos. Possuía importância militar, constatada pela presença de um castelo, edificado por D. Afonso Henriques em 1135. A cidade de Leiria se desenvolveu e cresceu em torno da igreja de S. Martinho, na base do morro do castelo. As ruas foram organizadas em função dessa igreja e da várzea do rio Lis. Nesses espaços, já se praticava o comércio desde o século XII (Margarido,1988). Portanto, o espaço urbano de Leiria era relevante centro econômico redistribuidor dos excedentes produzidos.

Consta nos anais do Município de Leiria que as feiras serviam como oportunidade de abastecimento de produtos do comércio local, como festa, sociabilidade e onde as moças compravam o seu enxoval.

O foral de 1142, dado pelo Rei Afonso Henriques ao povoado, não se referia às feiras, mas apenas aos "comerciantes locais que iam vender os artigos do seu comércio a outros povoados". Nesse foral, ainda se lê: "Mercador de Leiria não pague portagem nas terras do Rei".

A feira de Leiria foi criada em 1295 (Anais do Município de Leiria: 15) pelo Rei D. Dinis, ao mesmo tempo em que as de Vila Flor, Alvito, Sernancelhe e outras. Conforme documentos da Câmara Municipal de Leiria e entrevista junto ao departamento de feiras e mercados, realizam-se atualmente no concelho, além das feiras anuais, 15 feiras semanais, representadas a seguir (fig. 1). 


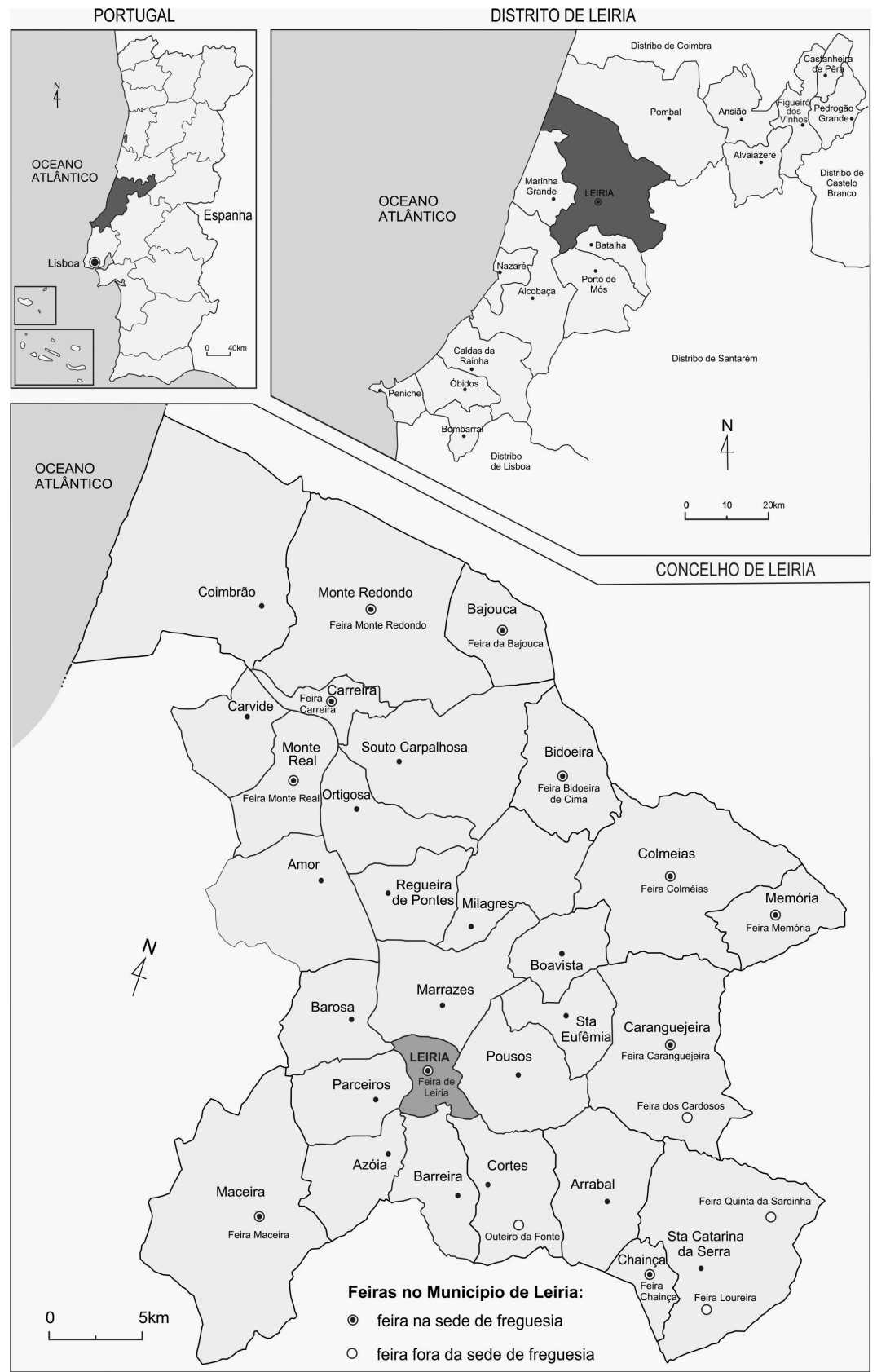

Fig. 1 - Localização das feiras no concelho de Leiria.

Fig. 1 -Location of fairs in the Leiria County.

Fonte: Camara Municiopal de Leiria, sector de feiras e mercado (2012) 


\section{OS FEIRANTES E O ESPAÇO PÚBLICO}

A ocupação do espaço público significa a forma como o homem interioriza a imagem desse espaço e como age, reage e o interpreta, apropriando o espaço público, fundamentalmente nas relações que os indivíduos mantêm com o mesmo. A luta dos feirantes pela ocupação do espaço público depende da avaliação que estes fazem do espaço quanto à localização estratégica para sua atividade comercial. De facto, apropriar-se significa tomar para si, tendo um propósito a ser alcançado.

Nas últimas décadas, as ruas se "fecharam" em centros comerciais, shoppings, hipermercados, entre outras atividades econômicas praticadas em grandes superfícies, espaços privados com consumidores seletos. Detentoras de uma organização e estrutura complexa, com elevados investimentos, as grandes superfícies comerciais prosperam em Leiria, demonstrando força e concentração financeira e comercial. Estes empreendimentos comerciais avançam sua hegemonia sobre o espaço urbano, em detrimento do pequeno comércio (incapaz de realizar os mesmos investimentos econômicos), que se insere nesse modo de produção capitalista, no contexto do capitalismo global.

Apesar de ser produto e efeito de um processo que formata o consumidor e molda o espaço-tempo de acordo com interesses do modo de produção capitalista, a feira escapa ao controle dos exímios planejadores dos interesses capitalistas (desejosos pelo seu fim, pois é considerado um espaço de ilegalidades, atraso, sujeira, desordem). Estes, incapazes de dissolver os efeitos de suas práticas econômicas, contribuem para a contradição interna da acumulação desigual do capital e, conseqüentemente, para as desigualdades sociais, espaciais e temporais, resultando em lutas de classes. Parafraseando Gilmar Mascarenhas de Jesus (2009: 162):

"Tomamos assim as representações sociais no sentido materialista e dialético, como âmbito de um embate sígnico, entre discursos, entre grupos sociais, numa sociedade e num território historicamente determinados. A representação, enquanto uma enunciação do objeto, e, no plano mais geral, uma apropriação simbólica da realidade, tem poder de conduzir as ações, de influenciar decisivamente a dinâmica socioespacial e também por ela se influenciar. Razão pela qual sempre se configurou como âmbito discursivo almejado, disputado."

Verifica-se, então, a ordem que se estabelece com as representações dominantes, que alimentam e (re)afirmam a "verdadeira" ordem da cidade: a hegemônica. A automação é o modo "civilizado" e moderno de ocupar a rua. Na maioria dos casos, o poder público investe na sociedade das ruas, (re)produzindo os interesses das classes dominantes. Jesus (2009) observa que, para intervir com autoridade, o poder público produz um discurso "competente", que "num primeiro momento cria e idolatra a feira, [...] para mais adiante a perseguir, como território de ilegalidades, atraso, sujeira, desordem" (Jesus, 2009: 162).

Em Leiria, verifica-se a descentralização comercial (fig. 2) e desvitalização do centro histórico (Cachinho, 2002). A periferização da centralidade urbana, com a presença de supermercados, hipermercados, shopping centres e, entre outros, a 
própria feira de Leiria, reforça os interesses dos grupos empresariais, que se ajustam incessantemente sobre o espaço comercial urbano, garantindo grande diversidade de produtos no mesmo lugar, além de outras facilidades de comercialização (Pintaudi, 1999: 155). Conforme Singer (1997: 15-17), "a cidade não inventa o comércio mas muda-lhe o caráter [...] o desenvolvimento do capital e a expansão urbana constroem uma classe de produtores urbanos retirada originalmente do campo".

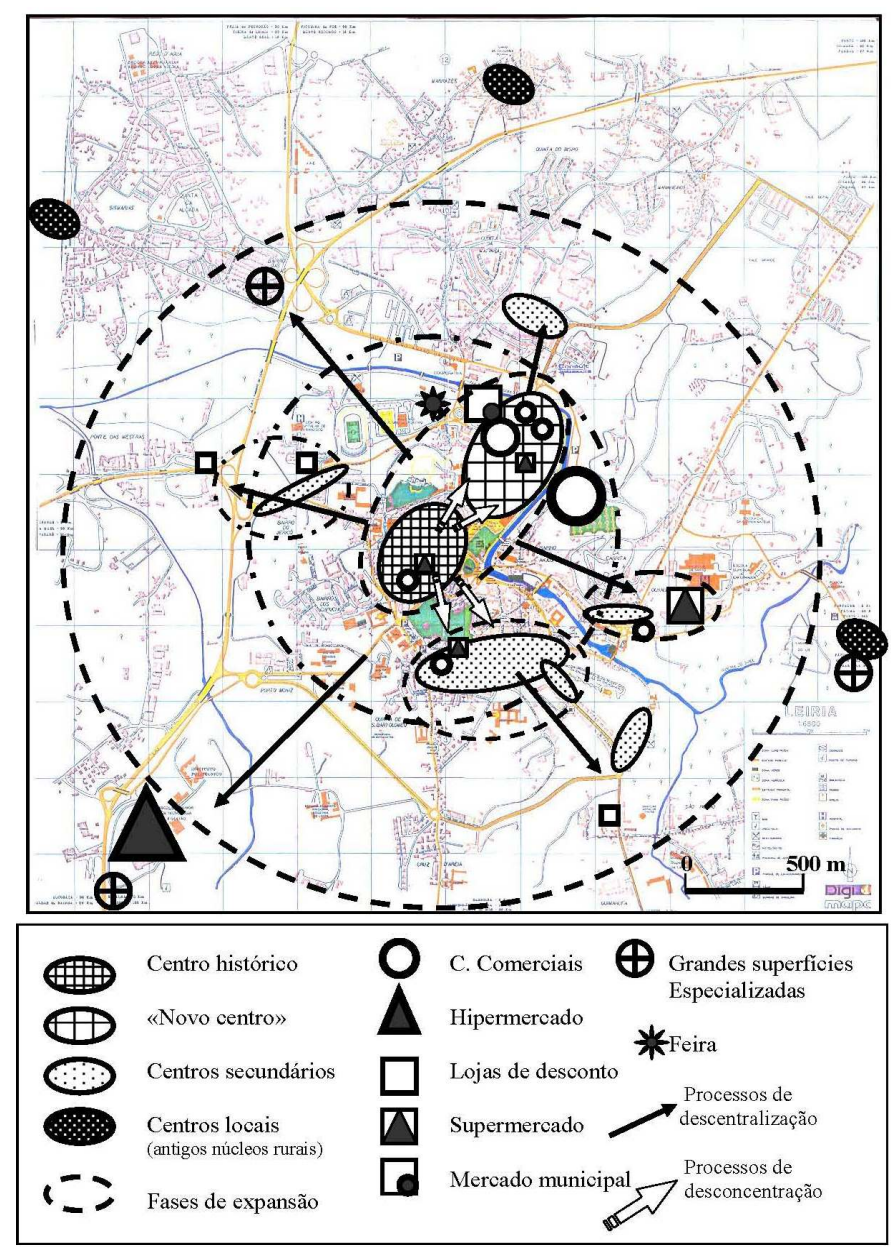

Fig. 2 - Organização espacial do comércio de Leiria. Fig. 2 - Spatial organisation of retailing in Leiria.

Org. por: Cachinho, 2002 (cedido pelo autor)

Em contrapartida, verifica-se o realojamento, a apropriação do espaço público pelos feirantes (fig. 3), numa inssurreição do uso (Seabra, 1996), apesar de a feira estar intimamente relacionada à legislação e sua aplicação (Rau, 1983). 


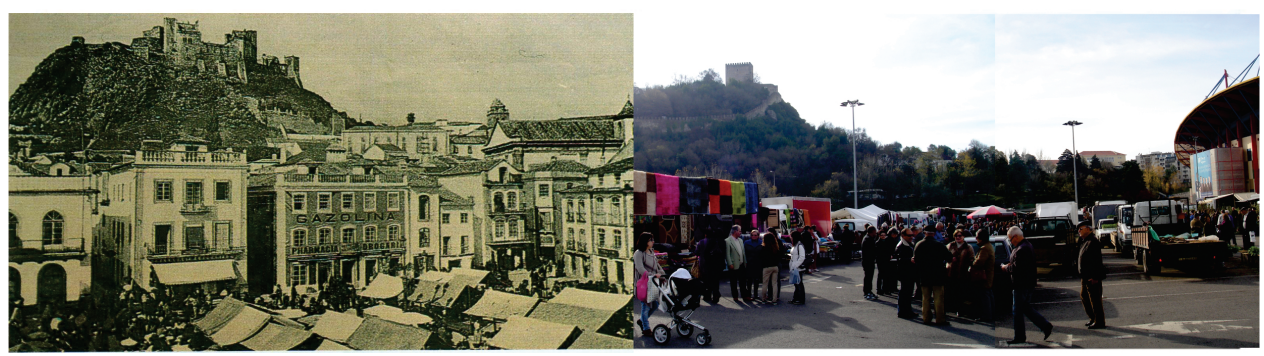

A feira no centro histórico de Leiria em meados de 1900: (Praça Rodrigues Lobo) Fonte: Costa, 1989
A feira de Leiria no estacionamento do Estádio Dr. Magalhães Pessoa em 2012

Fonte: Autor

Fig. 3 - Descentralização comercial e realojamento da feira de Leiria no espaço público

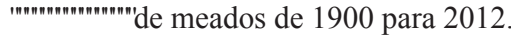

Fig. 3 -Decentralisation and commercial relocation of the Leiria fair within the public space

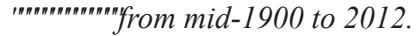

Lembra Jesus (2009) que, à concepção dominante de ordem segregadora e funcionalista circulatória da rua, se opõe o uso das camadas populares, que promovem outro sentido e significado ao espaço público. Com o aparecimento e intensificação do automóvel, o centro histórico de Leiria perdeu espaço de sociabilidade e de consumo (fig. 4).

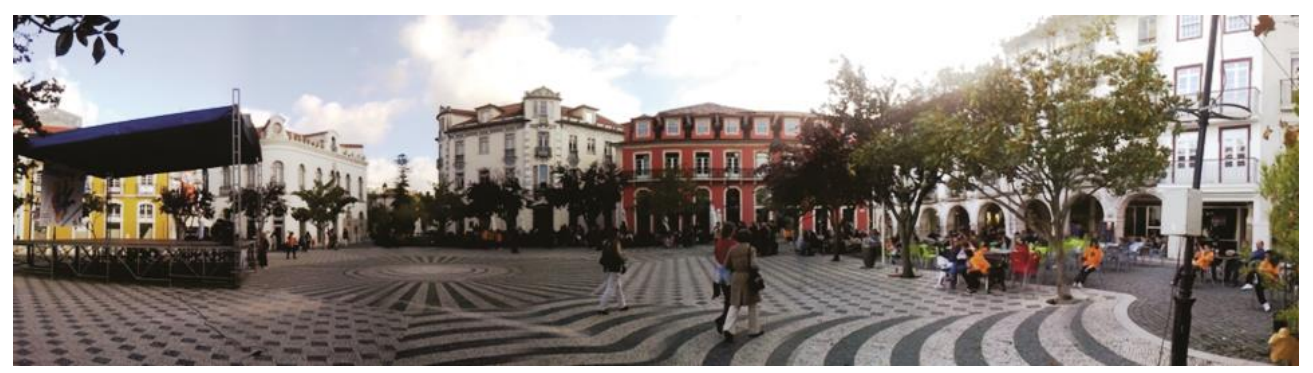

Fig. 4 - A pequena circulação de consumidores no centro histórico de Leiria Praça Rodrigues Lobo, Outubro de 2012.

Fig. 4 - The small movement of consumers in the historic center of Leiria Rodrigues Lobo Square, October 2012.

Fonte: Cachinho, 2012 (foto cedida pelo autor)

A intensificação do uso do automóvel permitiu que as grandes superfícies de comércio e de consumo, incluindo a feira, se instalassem em áreas cada vez mais distantes do centro urbano de Leiria. O significado da praça e do centro histórico deixa de ser lugar de encontro, de trocas e de socialização, para ficar sujeito à degradação e violência. 
Em outros países, a feira sofreu com as transformações decorrentes desse processo, sendo extinta em cidades como Buenos Aires (final da década de 1970), e minguando em diversas localidades do Brasil, como Salvador (BA) e Fortaleza (CE) (Jesus, 2009: 172).

A feira representa, na realidade, a apropriação do espaço público. É uma forma coletiva de uso desse espaço, que se contrapõe ao paradigma dos modernos espaços de consumo das grandes superfícies, à segregação do espaço urbano, tornando a cidade mais viva. O realojamento dos feirantes no espaço público é um processo essencial na luta pela sua sobrevivência e da cidade, espaço de encontros, de convivialidade, festa e animação.

\section{A MOBILIDADE DE FEIRANTES E CONSUMIDORES}

Acreditamos que a globalização é uma realidade que (re)organiza o espaço. Portanto, sentimos a necessidade de analisar as realidades do mundo do comércio e do consumo, no que tange às mobilidades de feirantes e consumidores da feira de Leiria. Segundo Milton Santos (2000: 79):

"no mundo da globalização, o espaço geográfico ganha novos contornos, novas características, novas definições. E, também uma nova importância, porque a eficácia das ações está estreitamente relacionada com a sua localização. Os atores mais poderosos se reservam os melhores pedaços do território e deixam o resto para os outros."

Conforme Bauman (1999: 8), a atualidade está marcada por esta incessante mobilidade resultante da globalização, a cujas consequências estamos sujeitos:

"Todos nós estamos, a contragosto, por desígnio ou à revelia, em movimento. Estamos em movimento mesmo que fisicamente estejamos imóveis: a imobilidade não é uma opção realista num mundo em permanente mudança. E, no entanto, os efeitos dessa nova condição são radicalmente desiguais. Alguns de nós tornam-se plena e verdadeiramente 'globais'; alguns se fixam na sua 'localidade' - transe que não é nem agradável nem suportável num mundo em que os "globais" dão o tom e fazem as regras do jogo da vida."

A mobilidade populacional pode-se tornar um tema complexo, decorrente das inúmeras dificuldades que se enfrentam ao abordar este aspecto da dinâmica demográfica. Rocha (1998: 14-15), utilizando diferentes variáveis distingue dois tipos de mobilidade da população: a horizontal e a vertical. Na primeira categoria integra, por um lado, a mobilidade física, que se reproduz em espaços concretos, podendo ir da "macromobilidade física", ou seja, da escala internacional (migrações) à "micromobilidade física", escala local (movimentos pendulares casa-trabalho) e, por outro lado, a mobilidade centrada no trabalho, que ocorre no âmbito da qualificação dos indivíduos, do seu status profissional e de outras condições ligadas à lógica capitalista de acumulação. A segunda categoria integra a mobilidade social intimamente ligada à mudança do estatuto social dos indivíduos, sua posição na sociedade e na hierarquia de classes sociais. 
Para Ana Fani A. Carlos (2007: 17):

"O lugar é a base da reprodução da vida e pode ser analisado pela tríade habitante - identidade - lugar. A cidade, por exemplo, produz-se e revela-se no plano da vida e do indivíduo. Este plano é aquele do local. As relações que os indivíduos mantêm com os espaços habitados se exprimem todos os dias nos modos do uso, nas condições mais banais, no secundário, no acidental. É o espaço passível de ser sentido, pensado, apropriado e vivido através do corpo."

Reafirmamos o direito à feira, numa extensão do direito à cidade (Lefebvre, 1991), como modo de contraposição à organização capitalista da sociedade contemporânea, que se apresenta como "globalizada", insinuando uma pretensão de homogeneização dos espaços. A fragmentação capitalista dos espaços é fato inexorável e perverso que, de forma lenta e dolorosa, vai excluindo os pequenos produtores e comerciantes. A luta dos feirantes e dos consumidores pelo direito à feira, ao uso mais democrático e consciente de seus lugares, é um exercício de cidadania.

Segundo Lefebvre (2008: 27-28), a rua

“[...] é o lugar (topia) do encontro, sem o qual não existem outros encontros possíveis (...) teatro espontâneo (...). Nela, efetua-se o movimento, a mistura, sem os quais não há vida urbana, mas separação, segregação estipulada e imobilizada. Quando se suprimiu a rua, viu-se as conseqüências: a extinção da vida, a redução da cidade a dormitóro, a aberrante funcionalização da existência. [...] Na rua, e por esse espaço, um grupo (a própria cidade), se manifesta, aparece, apropria-se dos lugares, realiza-se um tempo-espaço apropriado."

A globalização, contrariamente ao senso comum, não é um fenômeno que aproxima as pessoas. Essa nova realidade, dentro do contexto atual do sistema econômico hegemônico, obriga muitos trabalhadores a percorrer longas distâncias para obter os recursos necessários à sobrevivência de sua família. Também é responsável por uma perda da identidade, da desterritorialização dos lugares e da relação direta entre as pessoas, ou seja, crescem as relações mediadas pelas tecnologias, que possibilitam o funcionamento das redes. A "vizinhança global" é, na verdade, uma "proximidade imposta", que "contribui somente para a contração do espaço, tempo e fronteiras, não para a expansão da harmonia comum ou valores compartilhados entre pessoas no mundo" (Kumaravadivelu, 2006: 133).

Inversamente às tendências comerciais globais, a feira de Leiria desenvolve funções de sociabilidade, de identidade, de identificação com o lugar e de centralidade temporária, oportunizando também troca de informações através das frequentes mobilidades de feirantes e consumidores (fig. 5). Assim, dentro do sistema de feiras, ela se torna um nó relevante como centralidade temporária na rede de comércio do município e da região, auxiliando e controlando todo um processo de produção de capital, a partir das necessidades e condições que se encontram no cotidiano dessas pessoas. Nesse sentido, esta feira representa referência na oferta de alimentos e de outras mercadorias, promovendo fluxos de feirantes entre diversas cidades da área de influência de Leiria. 


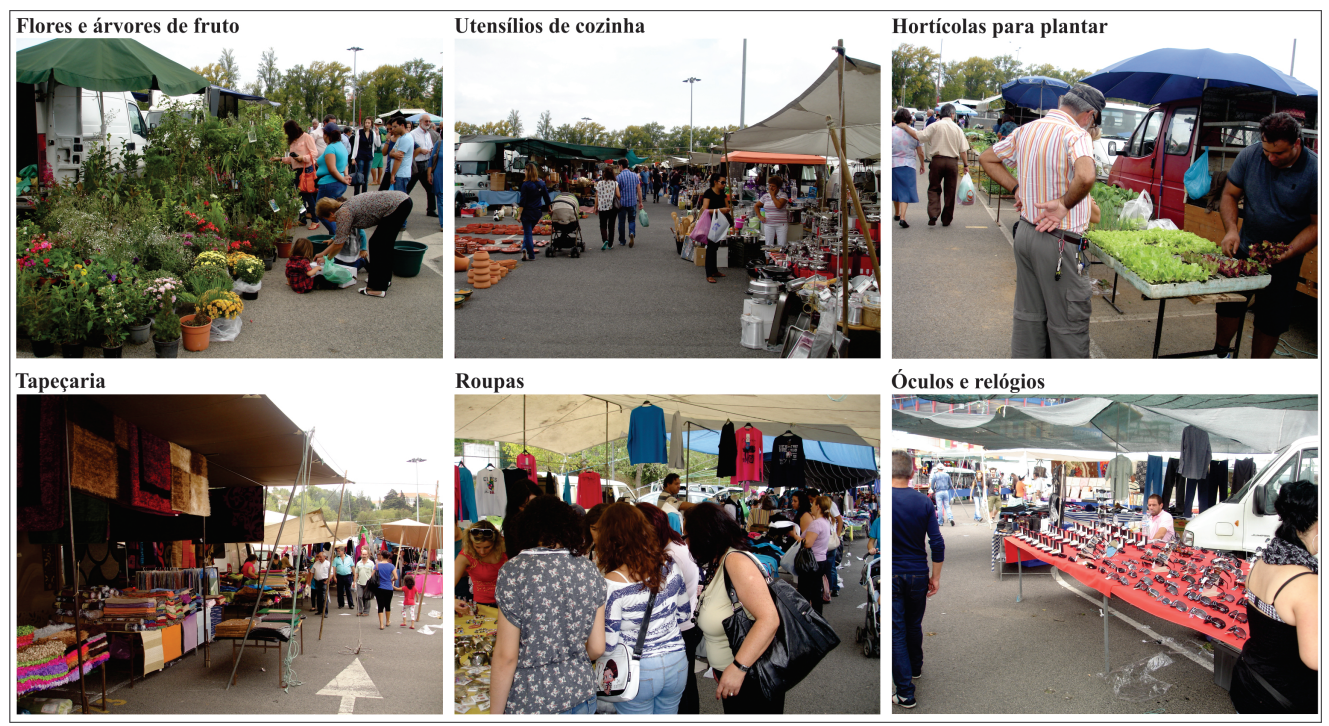

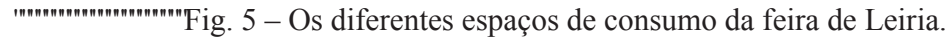

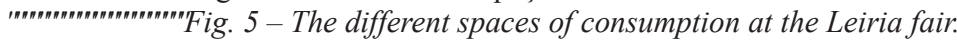

Fonte: Autor (Outubro de 2012)

A mobilidade é uma característica intrinsecamente vinculada ao feirante. Esta é de importância vital para a manutenção do tecido social urbano e culmina com a ocupação temporária do espaço público urbano para satisfazer às necessidades objetivas e subjetivas desses trabalhadores e dos consumidores que para lá também se mobilizam. A feira de Leiria não representa apenas mobilidade de trabalhadores, mercadorias e consumidores, mas também movimento de capitais, de coisas, de ideias, de comunicação, de desejos, de informações e de necessidades, estabelecendo, assim, importantes relações sociais, pessoais e profissionais.

Para que as trocas se realizem nas feiras é necessária a mobilidade e o encontro entre feirantes e consumidores. Desse modo, a troca não será apenas comercial, mas de ideias, palavras, experiências e sensações que fazem parte do encanto da feira: "E essa troca, que nos perdoe o comércio virtual (e-commerce), não pode prescindir do espaço físico para se materializar" (Vargas, 2001: 14).

Nesse contexto, a mobilidade dos feirantes e consumidores ocorre de forma circular. Particularmente, o feirante produtor de alimentos realiza seus deslocamentos, predominantemente entre o campo e a cidade, ou seja, é um movimento de vai e vem entre o "lugar de produção" (a propriedade) e o "lugar de comercialização e consumo" (as feiras).

Para Lefebvre (1991), o campo é lugar de produção, resultante de uma terra explorada pelas políticas urbanas e a vida da cidade: "A vida urbana compreende mediações originais entre a cidade, o campo, a natureza" (Lefebvre, 1991: 68). 
A mobilidade física do feirante pode ser identificada por diferentes tipos de círculos, constituídos entre as diversas feiras que o mesmo frequenta. Assim, no abastecimento da cidade de Leiria, essa mobilidade é comparável à função que o sangue exerce no corpo humano, transportando o oxigênio e os nutrientes. A feira de Leiria torna-se por algumas horas um coração econômico, uma centralidade temporária, para onde se dirigem centenas de consumidores.

Conforme entrevistas, os feirantes da feira de Leiria normalmente frequentam quatro ou cinco feiras durante a semana. Saem de suas casas, para atender aos consumidores de outros municípios, muitas vezes situados a mais de cem quilômetros de Leiria (fig. 6).
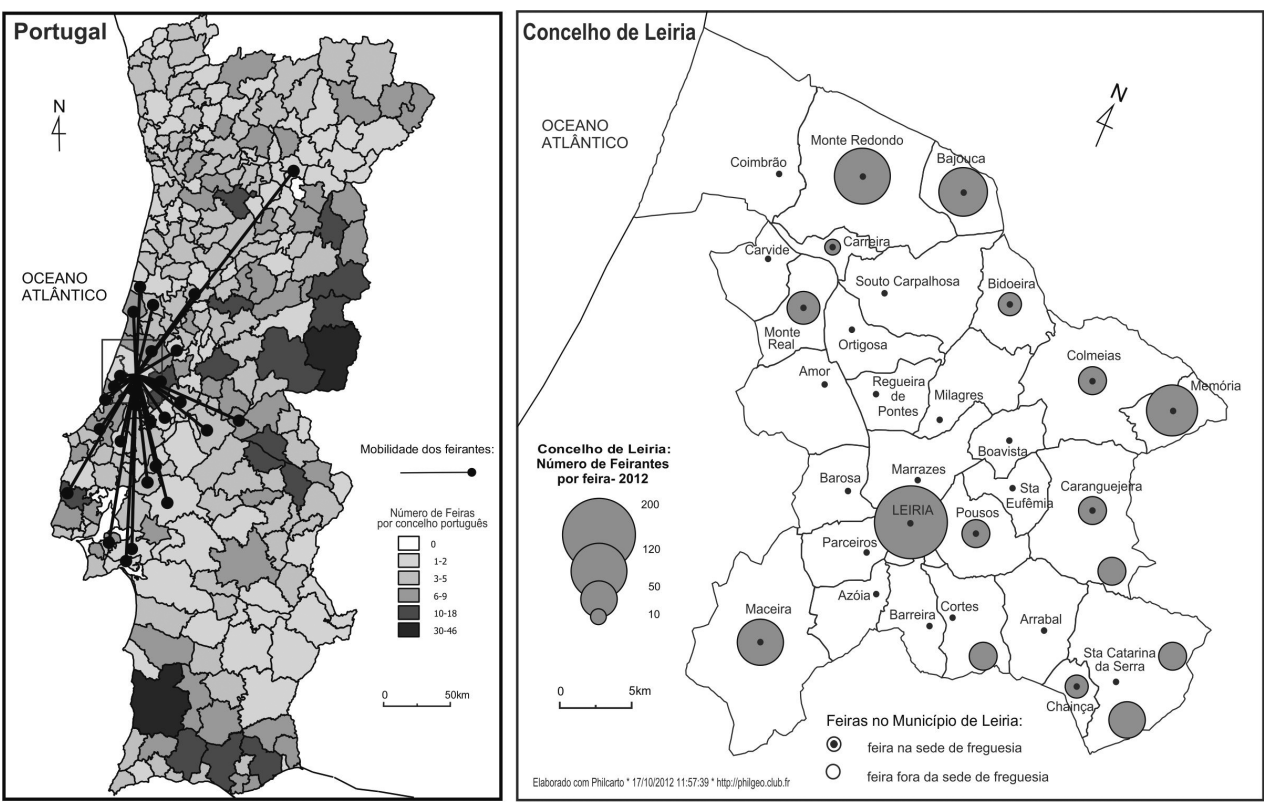

Fig. 6 - Mobilidade e participação dos feirantes de Leiria nas feiras dos concelhos de Portugal (2012).

Fig. 6-Mobility and participation of Leiria County merchants in various municipalities fairs in Portugal (2012).

Fonte: Instituto Nacional de Estatística e Câmara Municipal de Leiria - sector de feiras e mercado (2012)

A dinâmica socioespacial nas feiras de Leiria é diretamente influenciada por fluxos periódicos de pessoas e mercadorias, fazendo dessas feiras pontos nodais na venda de diversos produtos. As mobilidades são decisivamente importantes para $o$ abastecimento da urbe.

Como se pode verificar pela figura 7, entre os dias 15 de Outubro e 3 de Novembro de 2012, a feira do sábado é a que atrai mais consumidores, ultrapassando seguramente os 5000 frequentadores. As mulheres são a maioria, cerca de $60 \%$, e se interessam principalmente por artigos de vestuário e calçado. 
A circulação de consumidores se intensifica entre as 9 e as 11 horas, tornando a feira de Leiria um verdadeiro formigueiro humano. Os utentes (87\%) preferentemente escolhem o carro como forma de deslocação. Outros 13\% vão a pé ou utilizam outro meio de transporte.

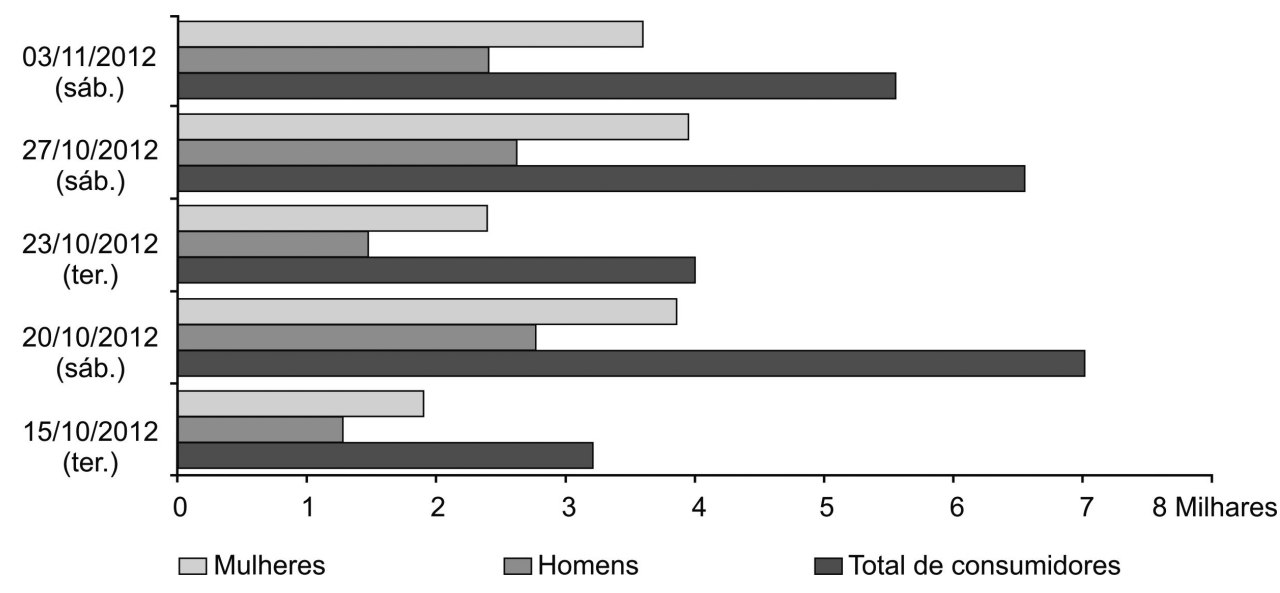

Fig. 7 - Número aproximado de consumidores na feira de Leiria em cinco datas.

Fig. 7 -Approximate number of consumers at Leiria fair in 5 dates.

Nos inquéritos aos consumidores, realizados entre 10 de Novembro e 1 de Dezembro de 2012, pode-se constatar que estes vêm, em alguns casos, de outras freguesias e até de outros concelhos (fig. 8), revelando uma deslocação de mais de vinte quilômetros. Buscam na feira de Leiria produtos com preços mais baixos, e a grande maioria declarou estar, de modo geral, satisfeita com a feira. Foram elogiadas a rapidez no atendimento, a competência e simpatia dos feirantes, além do estacionamento e dos bons preços. No entanto, limpeza, estética, conforto, instalações sanitárias e segurança foram assinalados como aspectos a serem melhorados. Também lembraram que as estacas e cordas, no meio das ruas da feira incomodam, dificultam a circulação e podem causar acidentes.

Alguns feirantes ressaltaram que às vezes, os "fregueses" vêm à feira para "desabafar" com os comerciantes sobre sua vida particular, e encontrar e conversar com os amigos, mostrando a dimensão social da feira de Leiria. Ocasionalmente, esses frequentadores acabam não comprando nada.

Os consumidores de Leiria geralmente compram gêneros de primeira necessidade, como hortaliças, frutas, e outros. Já os consumidores das freguesias vizinhas, além de comprar os produtos de necessidade básica, buscam também bens de aquisição mais ocasional relacionados com os artigos pessoais, como o vestuário e o calçado, ou com os de uso no lar, como os utensílios domésticos e os artigos de decoração. Neste sentido, pode-se dizer que a centralidade temporária criada pela feira se constrói em diferentes escalas: a intraurbana e a interurbana. 
Convém ressaltar que para $96 \%$ dos feirantes, a feira é seu único meio de sobrevivência, e aproximadamente $30 \%$ dos feirantes conservam atividades ligadas ao campo, constatando-se, assim, a importante relação cidade-campo. Ademais, pelo menos $70 \%$ dos produtos vendidos na feira são adquiridos através de intermediários; $10 \%$ produzem, mas também compram para vender. Estatisticamente observa-se uma expressiva relação entre feirantes da cidade e os feirantes do campo, que evidencia também a frágil distinção entre esses trabalhadores e seus espaços.

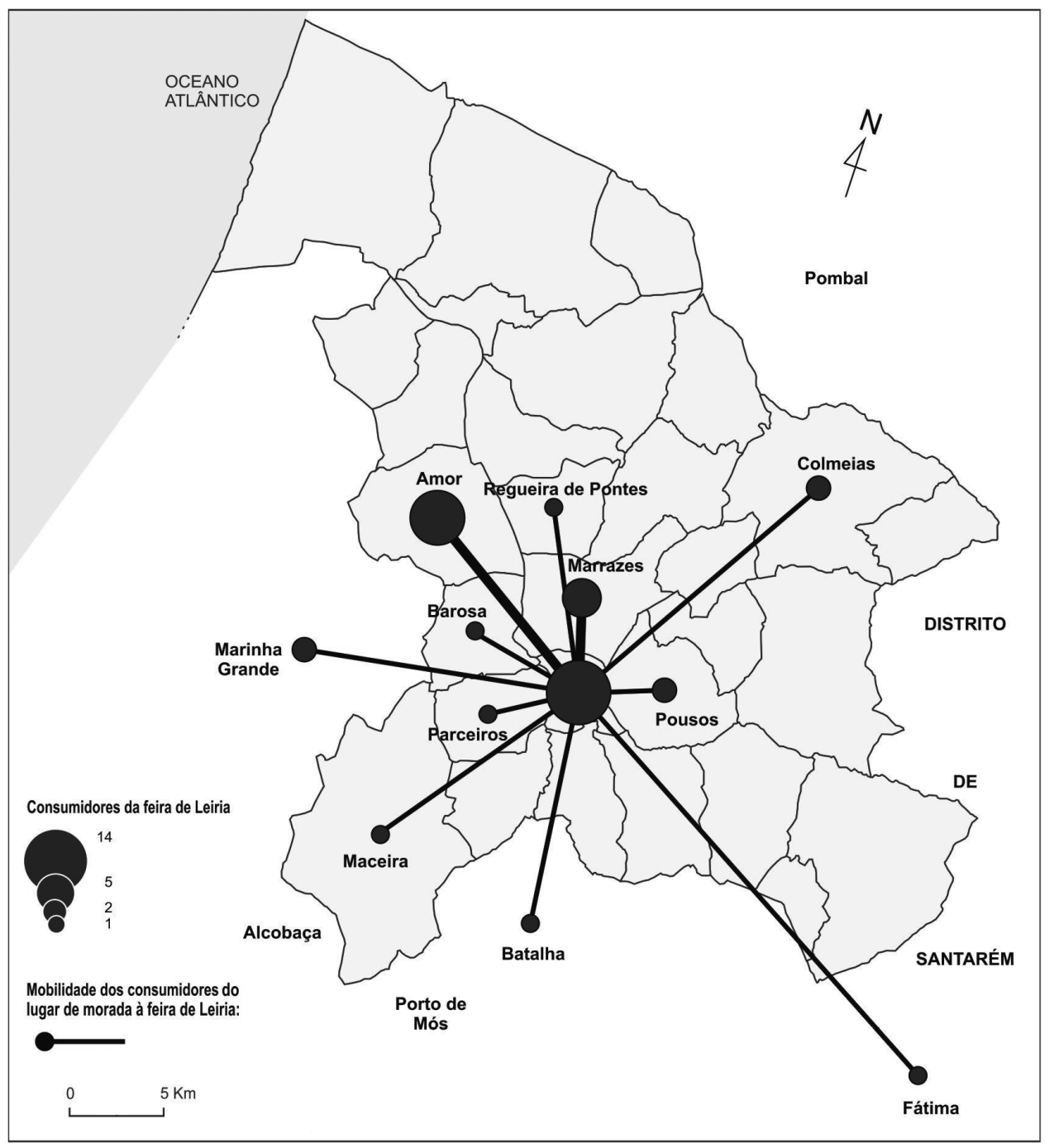

Fig. 8 - Origem e mobilidade dos consumidores da feira de Leiria - 2012.

Fig. 8-Leiria fair consumers' origin and mobility - 2012.

Fonte: Entrevistas a consumidores (2012) 


\section{CONSIDERAÇÕES FINAIS}

Os resultados desse trabalho da feira de Leiria, constituem parte relevante e indispensável de tese que se propõe a estudar a mobilidade da força de trabalho dos feirantes e dos consumidores de Maringá e Leiria, no contexto do capitalismo global. Deseja-se contribuir com reflexões sobre os conflitos entre os espaços de produzir, de comercializar, de consumir e de viver das feiras, função do processo direto dos deslocamentos humanos e do modo de produção capitalista e suas formas de regulação articuladas às outras instâncias da produção. Deste modo, contemporaneamente, as mobilidades do trabalho e dos consumidores ganham renovada importância, que nesse estudo está intimamente articulado aos espaços das feiras, condicionados pela configuração técnica do território no campo e na cidade, ditados por relações mais distantes. Essa geografia da mobilidade do trabalho e dos consumidores é um dado importante no entendimento da sociedade contemporânea.

As feiras são, ainda hoje, espaços de grande importância social, cultural e econômica, especialmente em tempos de crise, pois conseguem absorver parte dos trabalhadores urbanos desempregados e a produção dos pequenos produtores rurais. Por possuírem geralmente preços mais acessíveis também permitem atender aos consumidores com menor poder aquisitivo ou com dificuldades financeiras. Portanto, a feira de Leiria constitui uma relevante atividade econômica que promove desenvolvimento local e regional.

No novo milênio, o consumidor é o verdadeiro protagonista, ocorrendo uma recentragem na cultura, nas comunidades territoriais e nas novas tribos sociais. Debruçando-se sobre a maneira significativa de entender o indivíduo, o espaço e o consumo, Barata-Salgueiro e Cachinho (2009: 30) observam que:

"O poder simbólico do consumo tanto diz respeito às mercadorias como aos lugares que the servem de contexto e montra, estende-se à própria cidade ou a alguns dos seus territórios. De facto, a regeneração urbana transforma em mercadoria, com forte dimensão simbólica, os novos espaços de consumo e de lazer que substituem os velhos tecidos de produção e, ao fazê-lo, promove a cidade, tornando-a objecto de consumo e de troca."

Dialeticamente, as mercadorias e os lugares de consumo (re)produzem os sujeitos. Desse modo, desejamos contribuir para a formação de um raciocínio lógico acerca da manutenção desta prática milenar de comercialização ante os modernos supermercados, hipermercados e shoppings, existentes atualmente no espaço global de maneira geral e, também, no espaço estudado de Leiria, de forma específica.

Sabe-se que a feira não é uma economia discricionária e que os elementos do passado convivem com os do presente, adaptados às necessidades da lógica de um capitalismo de sobrevivência. Isso também resulta do estreitamento das relações do local com o global, uma vez que a nova lógica de produção acaba por formatar o consumidor, seus costumes e o consumo, além do próprio tempo e espaço.

$\mathrm{Na}$ feira de Leiria, o passado e o presente convivem, se sobrepõem, se confundem e se misturam, mostrando que a cidade sabe conviver com as diferenças, contrariando a produção dos espaços de comércio e consumo contemporâneos. 
Ultimamente tudo é global, e a feira parece não caber nessa escala de generalização, que a faz desaparecer do nosso olhar enquanto identidade, manifestação cultural e tradição, descontextualizando-a. É sabida a relevância da feira no papel de estruturação e reestruturação da cidade, e também a sua resistência às modernidades e às alterações de ordem econômica e política.

Assim, a feira de Leiria, embora no contexto do mercado, constitui e polariza a cidade na região como centro comercial, vinculando o consumidor de maneira mais próxima com o produtor, esboçando uma dimensão de humanidade qualitativamente diferente das relações monopolistas de alta produtividade ou de produção em escala. Também assume papel fundamental para o desenvolvimento humano e econômico, na medida em que, a partir dela, é possível identificar as formas de organização espacial e as mudanças ocorridas ao longo do tempo. Além disso, constitui um espaço democrático e mais humano, pois o consumidor tem a oportunidade de conhecer o produtor e a origem do alimento que consome. Portanto, as feiras, constituem espaços onde as relações sociais acontecem de forma mais intensa, ou seja, é o "espaço do acontecer solidário" (Santos, Souza e Silveira, 1994: 17). Para estes autores (1994), estas solidariedades definem usos e geram valores de múltiplas naturezas: culturais, antropológicos, econômicos, sociais, financeiros, entre outros. Enfim, a feira é o espaço onde os pequenos comerciantes, em particular o produtor, se realizam na cidade.

\section{BIBLIOGRAFIA}

Anais do Município de Leiria 2012 (documentos pertencentes ao concelho da cidade de Leiria)

Barata-Salgueiro T, Cachinho H (2009) As relações cidade-comércio: dinâmicas de evolução e modelos interpretativos. In Carreras $\mathrm{C}$, Pacheco S (org.) Cidade e Comércio: a rua comercial na perspectiva internacional. Armazém das Letras, Rio de Janeiro: 9-39.

Bauman Z (1999) Globalização: as conseqüências humanas. Jorge Zahar Ed, Rio de Janeiro.

Cachinho H (2002) O comércio retalhista português: pós-modernidade, consumidores e espaço. GEPE, Lisboa. (versão da Tese de doutorado apresentada à Universidade de Lisboa, em 1999).

Carlos A F A (2007) O lugar no/do mundo. FFLCH, São Paulo.

Corrêa R L (1994) A rede urbana. Editora Ática SA., São Paulo, $3^{\mathrm{a}}$ ed.

Costa L (1989) Leiria. Editoral Presença, Lisboa.

Derruau M (1982) Geografia humana. Editorial Presença, Lisboa, $3^{\text {a }}$ ed., Vol. II.

Harvey D (2005) A produção do espaço capitalista. Annablume, São Paulo.
Henriques R J S (2012) Comércio não sedentário, feiras e venda ambulante: um recurso a potenciar no Município do Cadaval. Relatório de investigação, na área da Geografia do Comércio e do Consumo. Instituto de Geografia e Ordenamento do Território da Universidade de Lisboa, Lisboa.

Huberman L (1976) História da Riqueza do Homem. ZAHAR Editores, Rio de Janeiro.

Jesus G M (2009) Negociando os usos e sentidos da rua: trajetória e representações da feira livre carioca. In Carreras C, Pacheco S M M (org.) Cidade e Comércio: a rua comercial na perspectiva internacional. Armazém das Letras, Rio de Janeiro: 161-176.

Kumaravadivelu B (2006) A lingüística aplicada na era da globalização. In Moita L (L.P.) Por uma Lingüística Aplicada Indisciplinar. Parábola, São Paulo.

Lefebvre H (2008) A revolução urbana. UFMG, Belo Horizonte.

Lefebvre H (1991) O Direito a cidade. Morais, São Paulo. 
Margarido A P (1988) Leiria: história e morfologia urbana. Câmara Municipal de Leiria. Leiria.

Pintaudi S M (1999) A cidade e as formas do comércio. In Carlos A F A (org.) Novos Caminhos da Geografia. Contexto, São Paulo: 143-159.

Rau V (1983) Feiras medievais portuguesas: subsidios para o seu estudo. Ed. Presença, Lisboa.

Rocha M M (1998) A espacialidade das mobilidades humanas - um olhar para o norte central paranaense. USP. Dissertação de Doutoramento, Faculdade de Filosofia, Letras e Ciências Humanas, Departamento de Geografia.

Santos M (2000) Por uma outra globalização: do pensamento único à consciência universal. Record, Rio de Janeiro.

Santos M, Souza M A de, Silveira M L (1994) Território: fragmentação e globalização. Hucitec, São Paulo.

Seabra O C L (1996) A inssurreição do uso. In Martins J S (org.) Henri Lefexre e o retorno à dialética. Hucitec, São Paulo.

Singer P (1997) Economia política da urbanização. Ed. Brasiliense, São Paulo.

Vargas H C V (2001) Espaço Terciário: o lugar, a arquitetura e a imagem do comércio. Editora SENAC, São Paulo. 